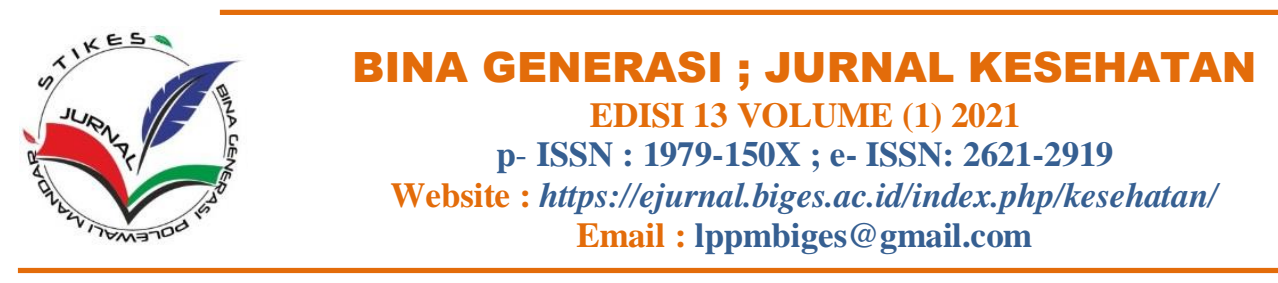

\title{
PENGARUH PENGGUNAAN KONTRASEPSI SUNTIK TERHADAP SEKSUALITAS AKSEPTOR DI RSIA MASYITA MAKASSAR
}

\author{
Dahniar $^{1}$, Firawati ${ }^{2}$ \\ ${ }^{1,2}$ STIKES Nani Hasanuddin Makassar \\ dahniarniar246@gmail.com \\ fhirara@ymail.com
}

\section{Keywords:}

Effect of

Injecting

Use, Against

Sexuality

\begin{abstract}
Birth control injections containing DMPA further increase the risk of experiencing sexual dysfunction. With the increasing number of injection family planning participants, it is necessary to conduct research on this issue. This study aims to determine the effect of using injectable contraceptives on acceptors at RSIA Masyita Makassar, the magnitude of the risk faced by DMPA injection respondents compared to those who used 1 month, and users of old and new contraceptives. This type of research uses purposive sampling technique and a sample of 35 respondents. The instrument used is a questionnaire sheet with a cross sectional approach. Data analysis was performed by univariate analysis with frequency distribution and bivariate with chi-square test with a significance level of $p<0.000$. The results showed that 28 people experienced sexual dysfunction or sexual disorders where there were 24 old users (68.6\%) and 4 new users (11.4\%). The results of the analysis showed that the age of the injection acceptor was associated with sexual dysfunction in women at RSIA Masyita Makassar.
\end{abstract}

\section{PENDAHULUAN}

Kontrasepsi suntik adalah cara untuk mencegah terjadinya kehamilan dengan melalui suntikan hormonal yang diberikan secara intra muscular di daerah gluteus, yaitu daerah bokong. Kontrasepsi suntik mengentalkan lendir serviks sehingga menurunkan kemampuan penetrasi sperma, menjadikan selaput lendir rahim tipis dan atropi, menghambat trasnportasi gamet oleh tuba, dan mencegah ovulasi. Adapun jenis kontrasepsi suntikan adalah kontrasepsi suntikan jenis kombinasi dan Depo medroksi progesteron acetat (DMPA) yang memiliki efektifitas yang tinggi dalam mencegah kehamilan (Aldriana \& Azmariza, 2017).

Disfungsi seksual merupakan adanya gangguan pada salah satu atau lebih fungsi seksualitas. Didalam fungsi seksualitas yang dinilai dsiantaranya adalah gairajh seksual/libido, orgasme, kepuasan, dan rasa sakit (Restu arahman, 2015).

Menurut world Health Organization (WHO) jumlah penggunaan kontrasepsi suntik di seluruh dunia yaitu sebanyak 4.000 .000 atau sekitar 45\%. Di indonesia kontrasepsi suntikan merupakan salah satu kontrasepsi yang populer. Kontrasepsi suntik yang paling banyak digunakan adalah jenis kontrasepsi suntikan Depo Medroxy Progesterone Acetate (DMPA) dan kontrasepsi suntik kombinasi (Aldriana \& Azmariza, 2017).

Menurut Association Of South East Nations (ASEAN) penggunaan kontrasepsi telah meningkat diberbagai dunia, terutama di Asia, Amerika Latin dan terendah di Sub- 
Sahar Afrika. Secara global, penggunaan kontrasepsi modern telah meningkat secara tidak signifikan dari 54\% pada tahun 1990 menjadi $57,4 \%$ pada tahun 2014. Secara rasional proporsi pasangan usia subur 15-49 tahun melaporkan penggunaan metode kontrasepsi modern telah meningkat minimal 6 tahun terakhir. Afrika mengalami peningkatan dari $23,6 \%$ menjadi $27,6 \%$ di Asia telah meningkat dari $60,9 \%$ menjadi $61,6 \%$, sedangkan Afrika latin dan karibia naik sedikit dari $66,7 \%$ menjadi $67,9 \%$ perempuan di Negara-negara berkembang diperkirakan 225 juta ingin menunda17 atau menghentikan kesuburan tapi tidak menggunakan metode kontrasepsi apapun dengan alasan sebagai berikut: Terbatasnya pilihan metode kontrasepsi dan pengalaman efek samping. Kebutuhan yang belum terpenuhi untuk kontrasepsi masih terlalu tinggi (Badan Kependudukan dan Keluarga Berencana Nasional, 2018).

Indonesia menjadi negara dari penduduk terbanyak, jauh diatas 9 negara ASEAN. Dengan angka fertilitas atau total fertility rate (PFR) 2,6 indonesia masih berada diatas rata-rata TFR negara asea yaitu 2,4. Data SDKI (survai demografi dan kesehatan nasional) menunjukan tren prefalansi penggunaan alat kontrasepsi atau contracetife prefalence rate (CPR) di indonesia sejak 1991 sampai 2012 cenderung meningkat, sementara tren angka fertilitas atau total fertiliti rate (TFR) cenderung menurun. Tren ini menggambarkan bahwa meningkatnya cakupan usia 15-49 tahun yang melakukan KB sejalan dengan menurunnya angka fertilitas. (Maryanti dkk, 2015)

Di Indonesia kontrasepsi suntik merupakan metode kontrasepsi hormonal yang paling digunakan. Hal ini dapat terlihat berdasarkan jumlah peserta KB aktif di indonesia tahun 2014 berjumlah 35.202.908 (74,87\%), 47,57\% menggunakan kontrasepsi suntik, kontrasepsi pil $(23,58 \%)$ dan implant $(10,46 \%)$. Sedangkan penggunaan metode non hormonal terbilang sedikit dibandingkan metode hormonal yaitu IUD $(11,07 \%)$, MOW $(3,52 \%)$, kondom $(3,15 \%)$ dan MOP $(0,69 \%)$. Hal tersebut dapat menjadi indikator bahwa KB suntik merupakan pilihan utama peserta $\mathrm{KB}$ untuk mencegah kehamilan dan mengatur kesuburan.

Data yang diperoleh dari Dinas kesehatan Provinsi Sulawesi Selatan tahun
2017, Pasangan Usia Subur (PUS) sebanyak 1.246.293 orang dan Jumlah peserta KB aktif sebanyak 764.005 orang yang meliputi KB suntik sebanyak $429.295 \%$ (56,19\%), PIL sebanyak 152.968 orang $(20,02 \%)$, Implan sebanyak $69.55399,10 \%$ ), intra uterin device (IUD) sebanyak 25.078 (3,28\%), kondom sebanyak $15.823(2,07 \%)$, metode opratif wanita (MOW) sebanyak $35.28 \quad(4,26 \%)$, metode opratif pria (MOP) sebanyak 12.132 $(1,59 \%)$ (Badan Kependudukan dan Keluarga Berencana Nasional, 2018).

Berdasarkan latar belakang tersebut, Saya tertarik untuk melakukan penelitian dengan judul pengaruh penggunaan kontrasepsi suntik terhadap seksualitas akseptor di RSIA Masyita Makassar.

\section{METODE PENELITIAN Jenis dan Metode Penelitian}

Jenis penelitian ini menggunakan penelitian deskriftif dimana suatu metode penelitian yang dilakukan dengan tujuan utama untuk membuat gambaran atau deskripsi tentang suatu keadaan secara obektif, sistematis, dan akurat (sulistrianingsi, 2011).

\section{Lokasi Dan Waktu Penelitian}

Penelitian ini bertempat di RSIA Masyita dilaksanakan pada bulan Oktober Desember tahun 2020.

\section{Populasi dan Sampel}

Populasi dalam penelitian ini adalah semua ibu akseptor KB suntik sebanyak 40 responden. Berdasarkan populasinya dapat di ambil sampel sebanyak 35 responden. Penelitian ini menggunakan kriteria sampel purposive sampling yang merupakan teknik penentuan sampel dengan tujuan tertentu saja (Ayu Putri Ariani, 2014).

\section{Cara Pengumpulan Data}

Data primer

Adalah data yg dikmpulkan oleh peneliti dari objek yang ditelit, cara pengambilan data primer dalam penelitian ini yaitu dengan menggunakan kuesioner yang dibagikan kepada responden (Hidayat, 2014).

Data sekunder

Data sekunder adalah data yang diperoleh dari dokumen, publikasi yang sudah dalam bentuk jadi. Data hasil sensus adalah 
contoh data sekunder. Data skunder adalah data yang diperoleh melalui bahan kepustakaan. Dalam penelitian ini peneliti menggunakan data sekunder dimana data diperoleh dari buku register pada tahun 2019 tentang jumlah peserta akseptor KB suntik yang tercatat di RSIA Masyita Makassar (Hidayat, 2014).
Analisa Data

Analisa data berupa analisa univariat yaitu data yang diperoleh dari masing-masing variabel di masukkan ke dalam variabel frekuensi. Selanjutnya di lakukan analisa bivariat yaitu untuk mengetahui atau menguji pengaruh antara variabel independen dengan variabel dependen.

\section{HASIL DAN PENELITIAN}

Hasil Penelitian

a. Analisis Univariat

Table 4.1 Distribusi Frekuensi Berdasarkan Umur Responden diRSIA

Masyita

\begin{tabular}{rcc}
\hline Umur & Frekuensi & Persentase \% \\
\hline $22-35$ tahun & 22 & 62.86 \\
$36-40$ tahun & 13 & 37.14 \\
\hline Total & $\mathbf{3 5}$ & $\mathbf{1 0 0}$
\end{tabular}

Sumber. Data primer 2020.

Berdasarkan tabel 4.1 di peroleh data responden berdasarkan umur 22 - 35 tahun sebanyak 22 orang $(62,86 \%)$ dan umur 36 - 40 tahun sebanyak 13 orang $(37,14 \%)$.

Table 4.2 Distribusi Frekuensi Berdasarkan Pendidika Respondendi RSIA Masyita

\begin{tabular}{ccc}
\hline Pendidikan & Frekuensi & Persentase \% \\
\hline SD & 3 & 8.57 \\
SMP & 8 & 22.86 \\
SMA & 5 & 14.29 \\
S1 & 19 & 54.28 \\
\hline Total & $\mathbf{3 5}$ & $\mathbf{1 0 0}$
\end{tabular}

Sumber. Data primer 2020

Berdasarkan tabel 4.2 diperoleh data responden berdasarkanpendidikan yaitu pendidikan SD sebanyak 3 orang $(8,57 \%)$, SMP sebanyak 8 orang (22,86\%), SMA sebanyak 5 orang (14,29\%) dan SI sebanyak 19 orang $(54,28 \%)$.

Table 4.3 Distribusi Frekuensi Berdasarkan Pekerjaan Responden di RSIA Masyita

\begin{tabular}{ccc}
\hline Pekerjaan & Frekuensi & Persentase \% \\
\hline IRT & 31 & 88,5 \\
Wiraswasta & 4 & 11,4 \\
\hline Total & $\mathbf{3 5}$ & $\mathbf{1 0 0}$ \\
\hline
\end{tabular}

Sumber. Data primer 2020

Berdasarkan tabel 4.3 di peroleh data responden berdasarkan pekerjaan dimana pekerjaan IRT sebanyak $31(88,5 \%)$ dan Wiraswasta sebanyak 4 orang $(11,4 \%)$. 
Table 4.4 Distribusi Frekuensi Berdasarkan Pengaruh Penggunaan Kontrasepsi Suntik Terhadap Seksualitas Akseptor diRSIA Masyita

\begin{tabular}{ccc}
\hline $\begin{array}{c}\text { Pengaruh Penggunaan Kontrasepsi Suntik } \\
\text { Terhadap Seksualitas Akseptor }\end{array}$ & Frekuensi & $\begin{array}{c}\text { Persentase } \\
\mathbf{\%}\end{array}$ \\
\hline Ya & 27 & 77,15 \\
Tidak & 8 & 22,85 \\
\hline Total & $\mathbf{3 5}$ & $\mathbf{1 0 0}$ \\
\hline
\end{tabular}

Sumber. Data primer 2020

Berdasarkan tabel 4.4 yang memiliki pengaruh penggunaan kontrasepsi suntik terhadap seksualitas sebanyak 27 orang (77,5\%) dan yang tidak berpengaruh sebanyak 8 orang $(22,85)$.

Tabel 4.5 Distribusi Frekuensi Berdasarkan Waktu Penggunaan Kontrasepsi Suntik Terhadap Seksualitas Akseptor

\begin{tabular}{ccc}
\hline $\begin{array}{c}\text { Waktu Penggunaan Kontrasepsi Suntik } \\
\text { Terhadap Seksualitas Akseptor }\end{array}$ & Frekuensi & $\begin{array}{c}\text { Persentase } \\
\mathbf{\%}\end{array}$ \\
\hline Lama & 25 & 71,4 \\
Baru & 10 & 28,6 \\
\hline Total & $\mathbf{3 5}$ & $\mathbf{1 0 0}$ \\
\hline
\end{tabular}

Sumber. Data primer 2020

Berdasarkan tabel 4.5 waktu penggunaan kontrasepsi suntik terhadap seksualitas akseptor yaitu 25 orang $(71,4 \%)$ yang lama menggunakan .kontrasepsi suntik dan 10 orang $(28,6 \%)$ yang baru menggunakan kontrasepsi suntik.

b. Analisis Bivariat

Pengaruh Lama Penggunaan Kontrasepsi Suntik Terhadap Seksualitas

Akseptor Di RSIA Masyita Makassar

Tabel 4.6 Distribusi Frekuensi Berdasarkan Pengaruh Lama Penggunaan Kontrasepsi Suntik Terhadap Seksualitas Akseptor di RSIAMasyita Makassar

\begin{tabular}{|c|c|c|c|c|c|c|c|}
\hline \multirow{3}{*}{$\begin{array}{l}\text { Lama } \\
\text { Penggun } \\
\text { a }\end{array}$} & \multicolumn{4}{|c|}{$\begin{array}{l}\text { Pengaruh penggunaan } \\
\text { kontrasepsi suntik } \\
\text { terhadap seksualitas }\end{array}$} & \multicolumn{2}{|c|}{ Total } & \multirow[t]{3}{*}{$\alpha=0,05$} \\
\hline & \multicolumn{2}{|c|}{ Ya } & \multicolumn{2}{|c|}{ Tidak } & $\mathrm{n}$ & $\%$ & \\
\hline & $\mathrm{N}$ & $\%$ & $\mathrm{~N}$ & $\%$ & & & \\
\hline Lama & 24 & $\begin{array}{r}68 \\
6\end{array}$ & 1 & $\begin{array}{c}2 \\
9\end{array}$ & 25 & 71,5 & $P=0,000$ \\
\hline Baru & 4 & $\begin{array}{r}11 \\
4\end{array}$ & 6 & $\begin{array}{l}17 \\
1\end{array}$ & 10 & 28,5 & \\
\hline Total & 28 & 80 & 7 & 20 & 35 & 100 & \\
\hline
\end{tabular}

Berdasarkan tabel 4.6 diatas, menunjukkan bahwa dari 35 responden yang menggunakan kontrasepsi suntik diantaranya 25 orang (71,5\%) yang lama menggunakan kontrasepsi suntik diantaranya 24 orang $(68,6 \%)$ yang mengalami pengaruh disfungsi seksual dan 1 orang $(2,9)$ tidak mengalami disfungsi seksual sedangkan pengguna kontrasepsi suntik yang baru sebanyak 10 orang 
$(28, \%)$ diantaranya 4 orang $(11,4 \%)$ yang mengalami pengaruh disfungsi

\section{PEMBAHASAN}

\section{Pengaruh Penggunaan Kontrasepsi Suntik Terhadap Seksualitas Akseptor di RSIA Masyita Makassar}

Hasil penelitian tentang pengaruh penggunaan kontrasepsi suntik terhadap seksualitas akseptor di RSIA Masyita Makassar pada tabel 5.6 menunjukkan bahwa responden yang menggunakan kontrasepsi suntik diantaranya 25 orang $(71,5 \%)$ yang lama menggunakan kontrasepsi suntik diantaranya 24 orang $(68,6 \%)$ yang mengalami pengaruh disfungsi seksual dan 1 orang $(2,9)$ tidak mengalami disfungsi seksual sedangkan pengguna kontrasepsi suntik yang baru sebanyak 10 orang $(28, \%)$ diantaranya 4 orang $(11,4 \%)$ yang mengalami pengaruh disfungsi seksual dan 6 orang $(17,1 \%)$ yang tidak mengalami disfungsi seksual. Sehingga dapat kita ketahui bahwa Akseptor yang lama menggunakan Kontrasepsi suntik akan mengalami disfungsi seksual dan ini sejalan dengan penelitian yang dilakukan oleh Siti Hindun, Rosyati Pastuty, Aprilina dengan judul Risiko Disfungsi Seksual Pada Perempuan Pemakai Kontrasepsi Depo Medroxy Progesteron Acetate Di Puskesmas Basuki Rahmat Palembang Tahun 2011 yaitu Hasil penelitian menunjukkan bahwa prevalensi klien DMPA dengan disfungsi seksual sebesar 64,4\%. Umur dan paritas menunjukkan hubungan yang bermakna dengan disfungsi seksual, sedangkan pendidikan, pekerjaan dan lamanya penggunaan kontrasepsi secara statistik tidak bermakna. Maka dapat disimpulkan bahwa pemakaian kontrasepsi DMPA meningkatkan risiko mengalami disfungsi seksual sebesar 0,73 kali. Umur dan paritas mempengaruhi terjadinya disfungsi seksual dan secara statistik bermakna. Pendidikan, pekerjaan, dan lamanya penggunaan kontrasepsi secara statistik tidak menyebabkan disorder dan disfungsi seksual pada perempuan usia subur di Puskesmas Basuki Rahmat Palembang.

Penelitian yang telah dilakukan sebelumnya tentang hubungan pemakaian DMPA dengan gangguan fungsi seksual wanita diperoleh hasil yang masih beragam. Kontrasepsi bisa mempengaruhi fungsi seksual, terutama kontrasepsi hormonal yang seksual dan 6 orang $(17,1 \%)$ yang

tidak mengalami disfungsiseksual.

secara langsung dapat mempengaruhi faktor faktor seperti libido dan orgasme. Metode kontrasepsi hanya progesteron bekerja dengan menekan fungsi ovarium dan menurunkan produksi estradiol endogen yang mempengaruhi fungsi seksual dengan berkontribusi pada kekeringan vagina terutama pada wanita perimenopause (Higgins dan Davis, 2014).

Hasil penelitian Hartantik (2017) didapatkan bahwa ada hubungan antara lama pemakaian kontrasepsi DMPA dengan kejadian disfungsi seksual.Hasil penelitian ini sejalan dengan penelitian yang menunjukkan bahwa pada penggunaan jangka panjang DMPA terjadi perubahan atrofi pada endometrium dan mukosa vagina. Atrofi mukosa vagina dan vagina kering bisa menyebabkan nyeri seksual/dispareunia (Saptatangtrakul, et al., 2016). Pengaruh DMPA dalam jangka panjang terutama pada pemakaian lebih dari 3 tahun berhubungan dengan gangguan fungsi seksual. Penurunan atau masalahfungsi seksual pada akseptor KB hormonal meningkat seiring dengan durasi penggunaan kontrasepsi hormonal. Penurunan fungsi seksual setelah 6 bulan pertama pemakaian sebesar $53,60 \%$, satu tahun $70,80 \%$, 2 tahun 73,90\%, dan lebih dari 3 tahun sebesar 77,80\% (Hasan, et.al., 2014).

Kontrasepsi suntik DMPA lebih berpengaruh terhadap kejadian disfungsi seksual pada akseptor dibandingkan dengan penggunaan kontrasepsi lainnya. Pada penelitian didapatkan bahwa umur akseptor merupakan faktor yang paling mempengaruhi kejadian disfungsi seksual. Hal ini menunjukkan bahwa faktor penggunaan kontrasepsi suntik DMPA sebagai faktor independen tidak dapat berdiri sendiri dalam mempengaruhi kejadian disfungsi seksual. Apabila terjadi interaksi secara bersama-sama maka dapat meningkatkan risiko disfungsi seksual pada akseptor KB (Ningsi, dkk., 2012).

Berdasarkan hasil penelitian yang dipaparkan sebelumnya diketahui bahwa ada hubungan antara lama pemakaian DMPA dengan kejadian disfungsi seksual. Namun pada beberapa penelitian lain hubungan suntik DMPA dengan kejadian disfungsi seksual belum didapatkan secara pasti. Ott, et al 
(2011) berdasarkan penelitiannya tidak menemukan hubungan antara penggunaan kontrasepsi hormonal dan gairah/keinginan seksual. Kemungkinan yang terjadi adalah efek hormon lebih sedikit mempengaruhi keinginan seksual dibandingkan faktor perilaku seperti kualitas hubungan dengan pasangan. Penelitian serupa didapatkan bahwa hubungan suntik DMPA dengan berkurangnya gairah/hasrat seksual jika dibandingkan dengan IUD cooper belum dapat dipastikan. Berkurangnya keinginan/minat seksual pada akseptor implan dan DMPA kemungkinan berhubungan dengan komposisi hormon pada metode ini (Boozalis, et al., 2017). Walaupun kebanyakan perempuan kemungkinan tidak akan terpengaruh terhadap efek samping kontrasepsi, namun kemungkinan konsekuensi pada masalah seksual semestinya dipertimbangkan dengan pasien selama diskusi pilihan kontrasepsi (Kingsberg dan Woodard, 2015).

Penelitian ini juga seseuai dengan teori yang menyatakan bahwa Suntik DMPA yang mengandung hanya hormon progesteron berhubungan dengan gangguan fungsi seksual terutama pada pemakaian jangka panjang. Mekanisme kerja dari suntik DMPA sebagai alat kontrasepsi yaitu mencegah ovulasi, mengentalkan lendir serviks dan mengubah endometrium menjadi dangkal dan atrofi sehingga tidak layak sebagai tempat implantasi. Mekanisme tersebut pada beberapa wanita dirasakan sebagai keluhan yang berhubungan dengan efek samping $\mathrm{KB}$ berupa vagina kering, nyeri saat berhubungan, penurunan mood dan penurunan libido. Masalah yang dirasakan ini merupakan gangguan kesehatan yang dapat mempengaruhi kualitas hidup terkait dengan hubungan suami istri. dimana Siklus menstruasi sejak dini dipengaruhi sejak remaja dengan kebutuhan gizi. (fitriani \& Ofan, 2020) Gangguan yang terjadi pada salah satu atau keseluruhan selama siklus respon seksual ini disebut disfungsi seksual. Hasil penelitian sebelumnya terhadap hubungan lama suntik DMPA dengan disfungsi seksual masih beragam. Faktor - faktor lain yang berpengaruh pada disfungsi seksual yaitu faktor biologis (kondisi kesehatan, umur, system neuroendokrin), faktor psikologis (depresi dan kecemasan) serta faktor sosial (kebudayaan, nilai moral dan agama).
Dari penelitian yang telah dilakukan maka peneliti dapat berasumsi bahwa Ada pengaruh penggunaan kontrasepsi suntik terhadap seksualitasakseptor di RSIA Masyita Makassar.

Adapun luaran yang telah di capai dalampenelitian ini adalah:

Didapatkan hasil penelitian yaitu hasil analisis univariat menunjukan bahwa Akseptor suntik lama yang berhubungan dengan disfungsi seksual pada wanita dimana di dapatkan $P=0,000$

Adapun luaran yang akan dicapai pada laporan penelitian ini adalah sementara akan di masukkan ke jurnal nasional terakreditasi.

\section{KESIMPULAN DAN SARAN}

Berdasarkan hasil penelitian sebanyak 35 Ibu yang menggunakan kontrasepsi Suntik Lama penggunaan kontrasepsi suntik oleh respondendalam penelitian ini adalah sebanyak 25 orang $(71,5 \%)$ menggunakan KB lama atau 24 bulan. Hasil penelitian didapatkan 28 orang yang mengalami disfungsi seksual atau gangguan seksual dimana pengguna lama sebanyak 24 orang $(68,6 \%)$ dan pengguna baru sebanyak 4 orang $(11,4 \%)$. Hasil analisis univariat menunjukan bahwa Akseptor suntik lama berhubungan dengan disfungsi seksual pada wanita.

Di tempat penelitian harus di jelaskan kepada responden kusioner yang akan diisi agar memudahkan responden dalam mengisi kusioner

Bagi peneliti selanjutnya dapat melakukan kajian lebih dalam tentang KB suntik dengan menambah beberapa variabel penelitian.

\section{DAFTAR PUSTAKA}

Ayu Putri Ariani.2014.Aplikasi Metode Penelitian Kebidanan Dan Kesehatan Reproduksi.Saowaja Baru:Yogyakarta

Abdullah, Sarwenda, Jeavery Bawotong, dan Rivelino Hamel. (2013). Hubungan Pemakaian Kontrasepsi Hormonal dan Non Hormonal dengan Kejadian Kanker Serviks di Ruang D Atas BLU, Prof, Dr, R. D. Kandou Manado. Ejurnal Keperawatan (e-Kp) volume 1 nomor 1 Agustus 2013

Ari, Sulistyawati, Esty Nugraheny. 2014. 
Asuhan Kebidanan pada Ibu Bersalin. Jakarta: Salemba Medika.

Aldriana \& Azmariza. 2017. Hubungan Lamanya pemakaian kontrasepsi suntikan dengan kembalinyakesuburan pada post akseptor kontasepsi suntik di desa pasir utama kecamatan hamba hilir. Jurnal Dosen Prodi D III Kebidanan Universitas Pasir Pengaraian di akses 13 Februari 2020.

BKKBN. BKKBN [Internet]. 2017 [cited 2018 Jul 20]. Available from: https://www.bkkbn.go.id/pages/visidan-misi

BKKBN. 2018. Laporan tahunan KB Pasca Persalinan Provinsi Sumatera Barat tahun 2017. Padang: BKKBN Sumatera Barat.

Melba Arahman Restu, Sri Utami , Siti Rahmalia. 2015. Hubungan Penggunaan Kontrasepsi Suntikan 3 Bulan Terhadap Disfungsi Seksual. Riau

Dita Agil Antika.2014.Hubungan Pengguna KB Suntik Dengan Seksualitas Akseptor.Ponjong:Gunung Kidul

Khairun Nisa Berawi.2015.Analisa Hubungan Pengaruh Penggunaan AlatKontrasepsi Hormonal DenganDisfungsi Pada

Wanita.Juke.Kedokteran.Unila.ac.id.co $\mathrm{m}$ fitriani, 1., \& Ofan, H. (2020). status gizi berhubungan dengan siklus menstruasi remaja putri. Patria Artha Journal of Nursing Science, 36-41.

Marmi.2018.Pelayanan Keluarga Berencana.Yogyakarta:Celebang Timur.

Mega, Wijayanegara H. Asuhan Kebidanan Keluarga Berencana. Jakarta: CV. Trans Info Media; 2017.

Meilani, N, dkk. 2010. Pelayanan Keluarga Berencana, Yogyakarta, Fitramaya. Hidayat, A.A.. (2014). Metode penelitian keperawatan dan teknis analisis data.Jakarta : Salemba Medika

Rusmini, dkk. 2017. Pelayanan KB dan Kesehatan Reproduksi Berbasis Evidence Based. Jakarta: Trans Info Media.

Sulistrianingsi, 2011. Metode Penelitian Kebidanan Kuantitatif- Kuantitatif. Ed 1jilid 2. Yogyakarta: Graha Limu.

Sulistyawati, Ari, dkk. 2013.Pelayanan Keluarga Berencana. Jakarta: Salemba Medika.

Yanti Afiyanti.2016. Seksualitas Dan Kesehatan Reproduksi Perempuan.Leuwinanggung:Kota Depok

Zahra Zettira.2015.Hubungan Penggunaan Kontrasepsi 